\title{
Immunologic Epidemiology
}

National Cancer Institute

\section{Source}

National Cancer Institute. Immunologic Epidemiology. NCI Thesaurus. Code C18845.

The study of the role of the immune system in the development of disease. 